\title{
Expected scores in the rod-and-frame test: Fuel for the Immergluck-Pressey fire
}

GLEN M. VAUGHT, State University of Vew York at Oswego, New' York 13126

The distribution of 684 Rod-and-Frame Test scores for 684 college Ss (346 males and $33 \mathrm{~S}$ females) is given, and its implication for studies of field dependence and of sex differences in RFT scores is discussed.

A recent exchange between Immergluck (1968) and Pressey (1968) served to call attention to the apparent lack of consistency among those who employ the Rod-and-Frame Test (RFT) in determining an appropriate criterion for field (in) dependence. There are at least two important aspects of this criterion problem that emerged from the Immergluck-Pressey repartee. First, while field (in) dependence as measured by the RFT is by definition a dimension of performance along which people distribute themselves, there is still a need to discern meaningful reference points for purposes of forming identity groups and to facilitate replication. There has simply not been enough normative data available to the interested researcher in spite of the RFT's popularity as a research instrument. Second, as Pressey (1968) has suggested. it is not always easy to match $\mathrm{Ss}$ when a deviation of $10 \mathrm{deg}$ or more is required to define field dependence. He concluded that while there is a sex difference in the RFT (males are generally more field independent than females) few Ss, regardless of sex, produce deviations of $10 \mathrm{deg}$ or more. This, of course, poses a problem for those whose research design calls for a large number of Ss with extreme scores and who may not have access to large $S$ pools. The consequences of not knowing what to expect in RFT responding eventually lead to communication difficulties and compel investigators to compromise identity group differences.

The present report provides a means of further examining RFT scores for 684 college Ss ( 346 males and 338 females) taken from a variety of studies by the author. In contrast to the Pressey (1968) data, within-sex percentages of Ss who had a particular RFT score was also included in the present frequency distribution (see Table 1), and the $\mathrm{N}$ of the present study was significantly larger than Pressey's. However, the procedure used by Pressey was very similiar to the one used in this study with the exception of the number of trials for each S. Pressey used four trials per $S$ while the author administered eight trials. Each $\mathrm{S}$ was brought into a darkened room
Table 1

Frequency Distributions of Scores in the Rod-and-Frame Test (Series 3) for 346 Males and 338 Females. $N=684$

\begin{tabular}{lcccc}
\hline & \multicolumn{4}{c}{ Percent of the Cases } \\
\cline { 2 - 5 } RFT Scores & \multicolumn{3}{c}{ By Sex } & \multicolumn{2}{c}{ Within Sex } \\
\hline & Male & Female & Male & Female \\
$0.0-0.9$ & 2.19 & 1.17 & 4.33 & 2.37 \\
$1.0-1.9$ & 10.67 & 8.33 & 21.09 & 16.86 \\
$2.0-2.9$ & 10.67 & 7.02 & 21.09 & 14.20 \\
$3.0-3.9$ & 6.87 & 4.82 & 13.58 & 9.76 \\
$4.0-4.9$ & 4.24 & 5.41 & 8.38 & 10.95 \\
$5.0-5.9$ & 4.53 & 3.51 & 8.96 & 7.10 \\
$6.0-6.9$ & 3.51 & 3.07 & 6.94 & 6.21 \\
$7.0-7.9$ & 1.16 & 1.90 & 2.31 & 3.85 \\
$8.0-8.9$ & .58 & 1.61 & 1.16 & 3.25 \\
$9.0-9.9$ & .58 & 1.02 & 1.16 & 2.07 \\
$10.0-10.9$ & .44 & .15 & .87 & .29 \\
$11.0-11.9$ & .29 & 1.46 & .58 & 2.96 \\
$12.0-12.9$ & .15 & .29 & .29 & .59 \\
$13.0-0$ - & 4.68 & 9.65 & 9.25 & 19.52 \\
\hline
\end{tabular}

individually, blindfolded, seated in an upright chair placed $12 \mathrm{ft}$ in front of the RFT, and required to adjust the rod to the vertical in each of eight trials. The frame was tilted $28 \mathrm{deg}$ to the right or left and the starting position for the rod was randomized on each trial. Like Pressey, the apparatus used in all the studies from which these data were taken was the same, in this case, an 18-10 RFT manufactured by the Marietta Apparatus Company. The S's score was the average deviation (without regard to direction of the deviation) from true vertical on all eight trials.

The data contained in Table 1 tend to support Pressey's finding that while sex differences in RFT responding can still be observed, only a small percentage of Ss exhibited a consistent deviation of $10 \mathrm{deg}$ or more. Further, it is obvious that a large number of Ss would have to be tested before extreme scorers and/or groups could be labeled field dependent.

\section{REFERENCES}

IMMERGLUCK, L. Comment on "Figural aftereffects, illusions and the dimension of field dependence." Psychonomic Science, 1968, 11, 363.

PRESSEY, A. A reply to comments on "Figural aftereffects, illusions and the dimension of field dependence." Psychonomic Science, 1968, 11,364 . 